\title{
Inward international students in China and their contributions to global common goods
}

\author{
Lin $\operatorname{Tian}^{1} \cdot$ Nian Cai Liu ${ }^{1}$ \\ Published online: 11 March 2020 \\ (C) Springer Nature B.V. 2020, corrected publication 2020
}

\begin{abstract}
This study identifies the (global) common goods produced and augmented by inward student mobility and its relevance to national policies and strategies in China by interviewing 27 policy-makers, university leaders, and academics, as well as international students. Most importantly, it develops a new framework for interpreting inward student mobility through the lens of (global) common goods, with benefit, influence, and balance as the three key elements. The findings of this study indicate that inward international students contribute to global common goods in the aspects of cultural diversity, global talents, improved policies, and practices, etc. (benefit). Key policies related to inward international students are generally supportive, and meanwhile compatible with these global common goods to a large extent (influence). Though some problems and tensions are observed in this study, constructive solutions have already been proposed by both the Chinese government and HEIs (balance).
\end{abstract}

Keywords Inward international students $\cdot$ Student mobility $\cdot($ Global) common goods $\cdot$ Higher education $\cdot$ National policy

\section{Introduction}

\section{Internationalization of higher education and inward student mobility}

Under the influence of globalization since the beginning of the twenty-first century, the internationalization of higher education has become an unstoppable and irresistible trend. International student mobility, in its multiplicity of forms, continues to be a high priority of internationalization, which refers to students moving from a country of origin to a country of education for study in a limited time (Knight 2012). More specific, inward student mobility is

Nian Cai Liu

ncliu@sjtu.edu.cn

1 Shanghai Jiao Tong University, Room 241, Chen Ruiqiu Building, 800 Dongchuan Road. Minhang District, Shanghai 200240, China 
viewed from the perspective of the chosen country of study (that is, the favorite destinations), which brings a potential "brain-gain" (Murphy-Lejeune 2008).

There were about 5.3 million international students pursuing higher education overseas in 2017, comparing with 3.3 million in 2008 (OECD 2019). They have the potential to bring significant academic and economic implications, and their numbers are expected to grow continuously (Knight 2012). However, perhaps as important as the rising numbers of international students is the fact that the traditionally dominant destination countries for international students (e.g., the USA, the UK, Australia, etc.) face growing competition from newly industrialized countries like China, Russia, Singapore, and Malaysia. These countries, which once sent large numbers of students abroad, are gradually becoming recipients of international students, as a result of their efforts in promoting inward student mobility (de Wit et al. 2013; Abdullah et al. 2017). For instance, in 2017, China sent 608,400 students to study abroad while at the same time hosted 489,200 international students (Ministry of Education of China, 2018). In the same year, according to OECD (2019), Russia took the fourth largest market share of international education globally, with a percentage of 5\%, following the US (18\%), UK (8\%), and Australia (7\%). The primary motives for these countries' push on inward student mobility can be summarized as: enhancing international influence, promoting international exchanges, accelerating the process of building leading universities, and potentially generating economic gains (Cao et al. 2016; Abdullah et al. 2017; Choudaha 2017).

Though the economic benefit of inward international student flows is not a main focus for certain countries (e.g., China), it is the primary pursuit for many developed countries including the UK and Australia. Therefore, when imaging inward international students, the notions of "global education market" and "global student market" are often used, which underpin the commercial value of inward student mobility and ignore its function as cooperation and a "win-win" (Marginson 2016a). In fact, inward student mobility is not solely market-driven. It brings various academic and social benefits not only to the host country but to other countries, including the countries of student origin. In light of this, (global) common goods can be a more inclusive lens to understand inward student mobility, since this concept highlights collective endeavor, shared participation/engagement, diversity, inclusion, and responsibility (UNESCO 2015).

\section{Definition of common goods and its context in higher education}

The idea of "common goods" is of significance in describing (higher) education, as (higher) education requires active participation and collective endeavor in the process, which is compatible with the definition of common goods (UNESCO 2015; Tian and Liu 2019). Although closely related to the idea of public goods, the concept of common goods has its own specific meaning and implications ${ }^{1}$ (see Table 1). Common goods can be defined as goods that are characterized by a binding destination and necessary for the realization of the fundamental rights of all people, irrespective of any public or private origin (UNESCO 2015, p.77). "The good realized in the mutual relationships in and through which human beings achieve their well-being" (Hollenbach 2002, p.81), which is inherent to the relationships that exist among the members of a society tied together in a collective endeavor (UNESCO 2015, p.78). These goods are necessarily grounded in the cultural and social dimensions of a specific

\footnotetext{
${ }^{1}$ For a more detailed discussion on differences between public goods and common goods in educational context, see also Tian and Liu (2019).
} 
Table 1 A comparison between (global) public goods and (global) common goods

\begin{tabular}{|c|c|c|}
\hline & Public goods & Common goods \\
\hline \multirow[t]{2}{*}{ Principles/theories } & Equity and social justice & $\begin{array}{l}\text { Besides equity and social justice, also } \\
\text { solidarity and cooperation }\end{array}$ \\
\hline & Political economy theory & Philosophical and political perspective \\
\hline \multirow[t]{3}{*}{ Nature } & Can be enjoyed as individual goods & $\begin{array}{l}\text { Necessarily shared, both regarding production } \\
\text { and benefits }\end{array}$ \\
\hline & $\begin{array}{l}\text { Non-excludable and non-rivalrous in terms } \\
\text { of consumption of a commodity }\end{array}$ & $\begin{array}{l}\text { Non-excludable and non-rivalrous in terms of } \\
\text { participation and generation of the goods } \\
\text { themselves }\end{array}$ \\
\hline & The public quality is predetermined & $\begin{array}{l}\text { The common quality is dynamic and not } \\
\text { pre-existing }\end{array}$ \\
\hline \multirow[t]{4}{*}{ Governance } & $\begin{array}{l}\text { Public governance justified on the basis of } \\
\text { externalities which extend to all }\end{array}$ & $\begin{array}{l}\text { Shared governance justified on the basis of the } \\
\text { cultural and social value of a specific good }\end{array}$ \\
\hline & Result of the action of public institutions & $\begin{array}{l}\text { Result of the interaction of the different } \\
\text { components of society }\end{array}$ \\
\hline & Top-down approach & Bottom-up approach \\
\hline & Passive role of those who benefit & Active role of those who benefit \\
\hline \multirow[t]{2}{*}{ Value } & $\begin{array}{l}\text { Global public goods are quasi-universal in } \\
\text { terms of accessibility to countries, peo- } \\
\text { ple and generations }\end{array}$ & $\begin{array}{l}\text { Global common goods imply the } \\
\text { empowerment of all actors in a world } \\
\text { society who have a right to a fully informed } \\
\text { and critical participation }\end{array}$ \\
\hline & $\begin{array}{l}\text { Instrumental, can be treated as economic } \\
\text { resources }\end{array}$ & $\begin{array}{l}\text { Cannot be reduced to economic resources or to } \\
\text { factors of production because of intrinsic } \\
\text { social and relational value }\end{array}$ \\
\hline
\end{tabular}

Source: Adapted based on Locatelli (2018b)

community and are identified for their contribution to the "general interest", also to conditions of justice and well-being (Locatelli 2018a).

Deneulin and Townsend (2007) argue that a celebratory dinner, an orchestral, or a team sport can be thought as common goods. They then take the orchestra as an example to illustrate how a common good is produced and how its benefits can be enjoyed. The good itself, an orchestra, cannot exist without each musician playing their respective parts and performing collectively for the whole audience. In other words, the good exists in the shared action which generates it. Also, benefiting from such good is by participating in it, whether in the orchestra or audience. Hence, the shared action is both intrinsic (without the various musicians' participation and performance, the orchestra cannot exist at all) and instrumental (it is necessary, efficient, and convenient to perform as an orchestra) to the good itself, and its benefits (an orchestra; beautiful music; excellent performance) are generated from the course of that shared action. Such kinds of goods are intrinsically common in their production and their benefits, reflecting the distinct characteristics of intrinsic value and shared participation (Deneulin and Townsend 2007; UNESCO 2015). In other words, the benefits and burdens for the realization of common goods are intrinsically shared among all participants, thus the common quality of these goods is not preexisting but is dynamic and contingent, emphasizing a process of participatory democracy (Locatelli 2018a).

However, common goods may have a boundary and be confined to a given group/ community, since it is often socially embedded. Their creation and production are processes of collective participation. People who participate in these processes can benefit from them, and these participants form a community with common interest (Tian and Liu 2019). In light of this, global common goods are related to all people worldwide, highlighting the participation 
of all persons in a diverse and differentiated, yet solidaristic and collaborative, world society (Deneulin and Townsend 2007, p. 29), and perhaps fostering social inclusion, integration, tolerance, equality, and human rights at a global level (UNESCO 2015; Tian and Liu 2019).

Thus, higher education itself can be regarded as a (global) common good, because receiving higher education can be seen as a specific activity, and HEIs, educators, students, and other stakeholders involved in the process could jointly reap the benefits through shared participation (Tian 2019). Broadly speaking, the notion of common goods suggests the transformation of HEIs through greater engagement of communities, civil society, and other non-state actors in the decision-making and practices in order to build a more democratic educational system (Locatelli 2018a; Boyadjieva and Ilieva-Trichkova 2019). Apart from this, higher education as a common good is closely related to such concepts as equity, justice, solidarity, and inclusion (Walker and McLean 2013, Marginson 2016b). Also, the idea of common goods in higher education is especially important in the process of globalization and internationalization, because it refuses to be closed and conservative, encouraging global universities and educators to collaborate jointly and participate actively (Tian 2019).

The previous literature draws a picture of the general situation of the internationalization of higher education, but it does not give as much attention to inward student mobility from a common goods lens, and the (global) common goods which are created and increased by it are rarely spelled out. Through semi-structured interviews, this study aims to explore the (global) common goods generated and augmented by inward student mobility in China as well as relevant policies, regulations, and practices. This paper begins with the broad literature on the history and development of inward student mobility in China as well as relevant policies and strategies. Then, it presents the research method, procedures, and empirical data. The paper concludes by linking the findings to the previous literature, to deepen and extend the understanding of this topic.

\section{Review of literature}

\section{Inward student mobility in China: history, development, and key policies}

The recruitment of education for international students in China began in 1950 and went through a 70-year history, which falls into the following five periods with relevant national policies (see Table 2). Until now, China has educated a group of people who understand and respect the Chinese culture, and at the same time expand China's international influence, helping to enhance its international image (Jiang 2010b).

It can be assumed that before the reform and opening-up in 1978, the recruitment of and education for international students in China mainly served as a diplomatic tool for international exchanges and assistance. After the reform and opening-up, policies for international students studying in China gradually moved from closed to open, and the decision to accept and educate international students in China shifted from government to HEIs. Meanwhile, more than a few HEIs began to recruit self-funded international students, and the number of these students rose rapidly (Jin 2012). Later in the 1990s, several improvements were made in the international education system. For instance, in 1992, the HSK (Hanyu Shuiping Kaoshi, which is a standard Chinese language proficiency test) was used as a standard test for evaluating the language ability of international students. In 1996, the Ministry of Education established the China Scholarship 
Table 2 Five periods of inward student mobility in China (1950-present)

Periods Changes and development

I: Initial practice

(1950-1965)

II: Twists and turns

(1966-1977)

III: Low-speed progress (1978-1989)

IV: Establishing a new system (1990-1998)

\footnotetext{
V: Rapid development with well-designed policies (1999-present)
}

- China conducted more international exchanges with socialist countries in the former Soviet Union and developing countries in Asia and Africa. As a duty to fulfill international aid, China actively accepted a large number of international students from third world countries of Asia, Africa, and Latin America. China accepted 7259 international students from 70 countries.

- Key policies:

The Trial Regulations for International Student Education (1962)

Regulations on Accepting International Students to Study in Chinese HEIs (1963)

- The deterioration of the domestic economic environment and the uneasy political situation made the international education that just started in China faltered. Later in 1973, China's HEIs resumed the recruitment of international students. From 1973 to 1977 , China only accepted 2066 students from 77 countries.

- Key policy:

Interim Provisions on the Teaching and Management of International Students (1974)

- Reform and opening-up ${ }^{1}$ (in 1978) brought promising signs to China's higher education, and the education for international students gained a new direction. 120 HEIs in China received 14,273 international students from 124 countries.

- Key policies:

Administrative Measures for International Students (1985)

Regulations on Recruiting Self-Financed International Students (1989)

- With the formation of a self-operation system under the guidance of the government, international education in China entered the first period of rapid development. Three hundred thirty-nine HEIs in China accepted 234,691 international students from 164 countries, an increase of more than 15 times compared to the previous period.

- Key policies:

Proposed Measures for the Degree-Granting for International Students in China (1991)

- China entered the stage of mass education in 1999; later in 2011, China's accession to the WTO accelerated the integration process within the global economy, which significantly enhanced the internationalization of higher education. From 1999 to 2018, China accepted 4,835,463 international students from more than 200 countries and regions.

- Key policies:

Plan of Studying in China (2010)

Administrative Measures for the Enrolment and Cultivation of International Students by Schools (2017)

Sources: Cheng and Huang 2008; Yu 2009; Jin 2012

1 "Reform and opening-up" refers to a policy formulated in the Third Plenary Session of the 11th Central Committee in December 1978, aiming at conducting reforms domestically and implementing opening-up strategies in economy

Council, which specialized in organizing, funding, and managing Chinese students studying abroad and international students studying in China.

During the present period, policies for international students studying in China are more comprehensive, and efforts related to promoting inward student mobility yield positive results (Cheng and Huang 2008; Fang and Wu 2016). The number of international students in China has increased markedly, and their study in China is greatly supported by a number of policies. 
In 2018, the number of international students studying in China was 492,185, about 11 times when compared with 44,711 in 1999 (see Fig. 1). China has entered the 10 highest-ranked destination countries in the world of international education, with the majority of international students coming from South Korea, Thailand, and Pakistan in 2018 (see Table 3). In terms of policies, the Administrative Measures for the Enrolment and Cultivation of International Students by Schools issued in 2017 clarified various aspects of inward student mobility, concerning degree certificates, training methods, curriculums, and so on, further improving the management system for international students studying in China. In October 2018, China published the first and latest Quality Standards of Higher Education for International Students Studying in China, expecting to improve the quality and management of international education in China.

\section{Benefits created by international students and their relevance to common goods}

Knight (2012), Riaño et al. (2018) consider that international student mobility has brought diverse and plentiful benefits to students, home and host institutions, communities, and countries, for instance, international students can be portrayed as precious human capital to boost the host country's economy and also as sources of income for the higher education sector. Specifically, in the Chinese context, Fang and Wu (2016) consider that international students improve the level of internationalization of Chinese higher education. Also, they assume that international students not only increase the direct economic benefits but also stimulate the growth of related service industries such as catering, transportation, and tourism. Similarly, Jiang (2010a) notes that international students studying in China have the potential to create economic benefits, though this has not received sufficient attention in China and it lacks reliable official statistics. Han (2014), Ma and Zhou (2018) agree that international education in China has cultivated a large number of professional talents and develop

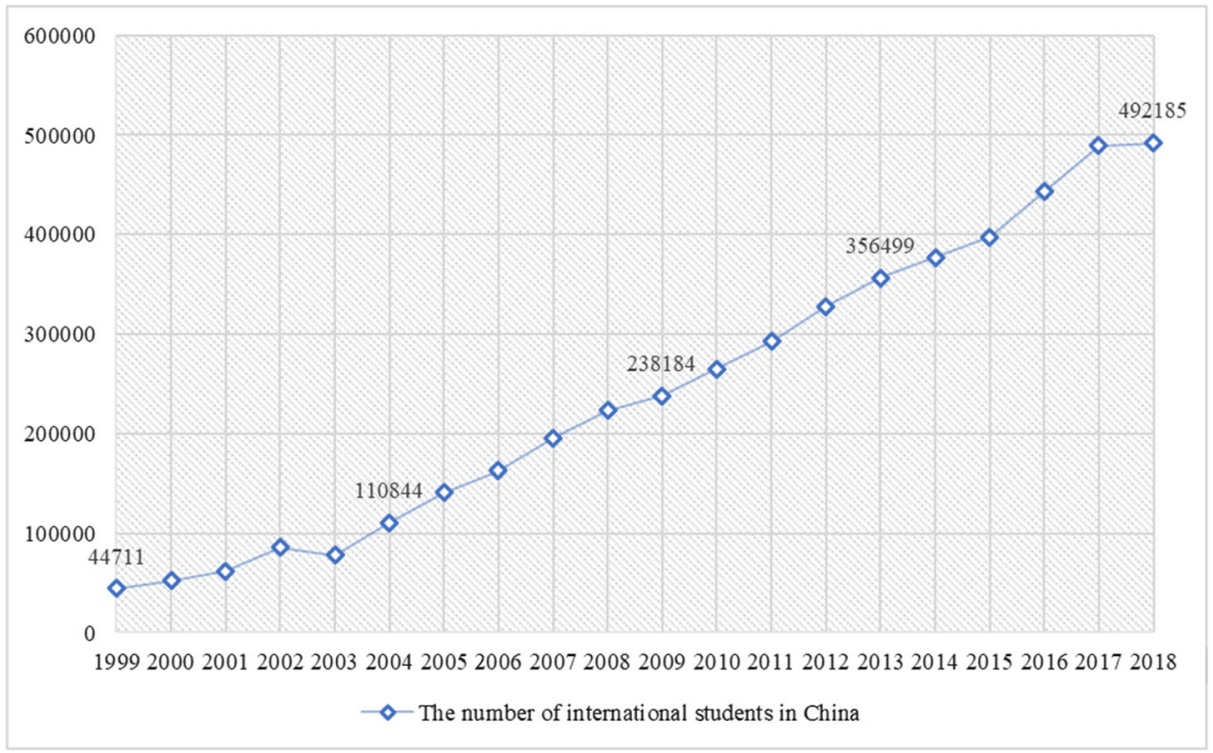

Fig. 1 The increase of international students in China (1999-2018)

Source: Ministry of Education of China (2000-2019) 


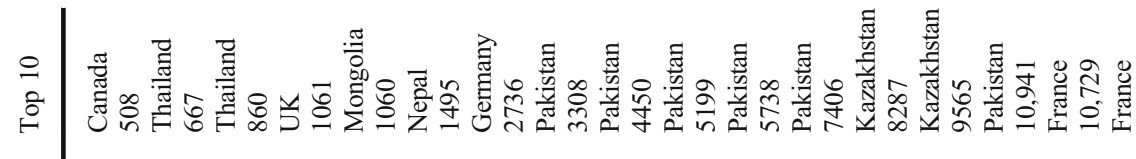

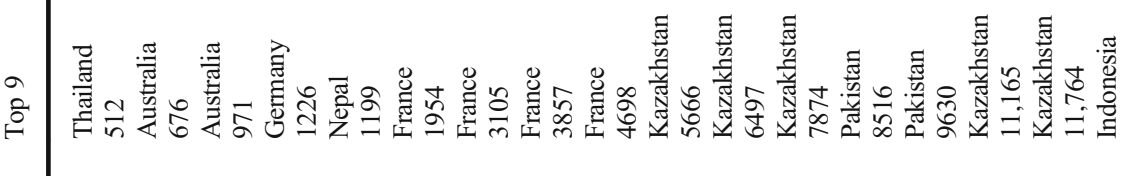

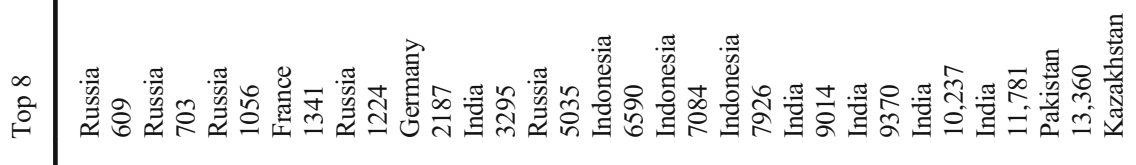

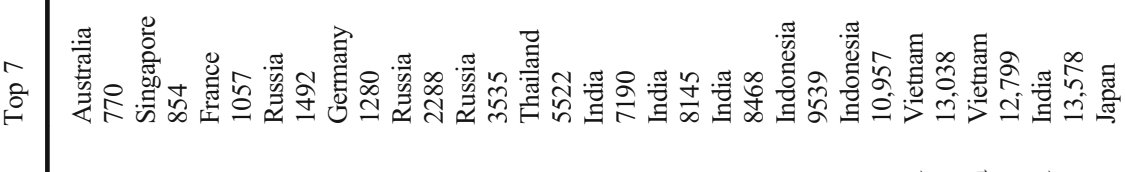

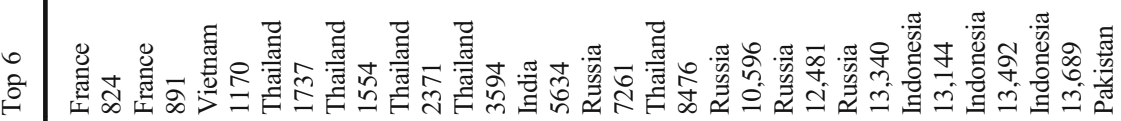

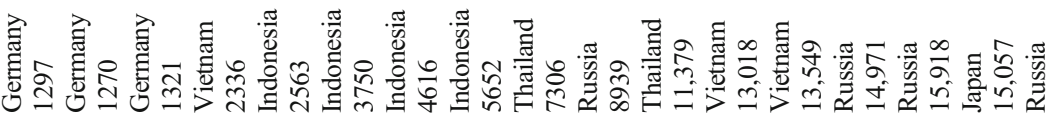

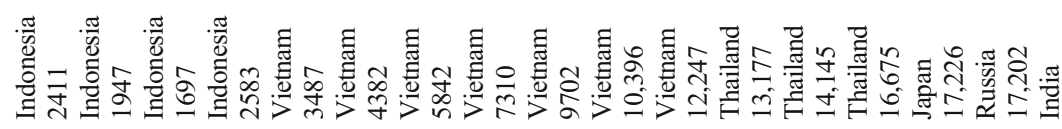

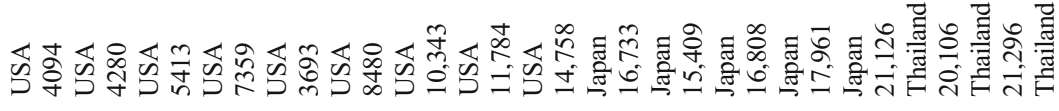
ॠ

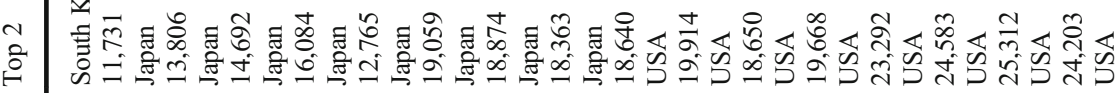

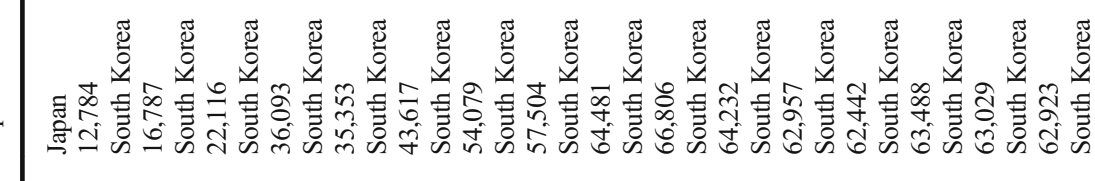

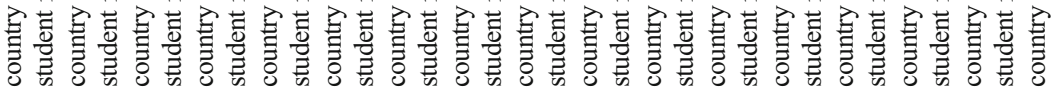
崖

范 





cooperative relations with other countries. Moreover, in recent years, under the background of Belt and Road Initiative, Chen and Wen (2018) suggest that international students play a central role in improving diplomatic relations and these students are human resources for Chinese enterprises overseas. However, research touches little on the common good(s) of inward student mobility in China, though some Chinese scholars have put forward that higher education contributes to (global) common goods in four respects: research outputs; public services; cultural inheritance and innovation; and talents (with global perspectives) (Tian and Liu 2019). The mobility of these global talents and cultural exchanges are conducive to building a community of shared future for humanity (ren lei ming yun gong tong ti) (Yang 2018).

In summary, the previous research has explored the history, development, and benefits of international students studying in China. This prior research lays a foundation for the present project. However, most research on inward students in China is theory-based, with less emphasis on empirical investigation; though some relevant research is policy-based and data-based, both the policies and data are out of date; Also, there is an absence of attempts to explore inward student mobility and relevant policies in China through a lens of common goods, which would generate both theoretical and practical contributions. Hence, in order to deeply understand the inward student mobility in China and (global) common goods, we formulated the following research questions:

(1) What are the (global) common goods of inward student mobility in China?

(2) How do the key policies, strategies, and regulations concerning inward international students relate to (global) common goods in China?

\section{Research design}

According to Kehm and Teichler (2007), institutions, people, and knowledge are the core elements of internationalization in higher education, and there is also a strong political undercurrent in the form of institutional strategies and national policies embedded in internationalization activities. Accordingly, in order to have a better understanding of inward student mobility in China, which is a key to higher education internationalization, the research method for this project mainly involves semistructured interviews (people-concerned), while at the same time focuses on policy documents related to international students mentioned by interviewees (policy-focused). Learning through policy texts from interviewees is a form of "lesson drawing", which can be defined as the voluntary act of transfer by rational actors working in specific political contexts (Benson and Jordan 2011).

\section{Participants}

This project adopted a purposive sampling to identify participants who were directly involved in inward student mobility. They were invited by the researchers through email. Twenty-seven Chinese people from the government and universities participated in the research. They were divided into four groups according to their affiliated institutions and positions (see Table 4) to ensure coverage of all relevant groups of people who might have a good understanding of inward international students and common goods in China. The study chose two universities at 
Table 4 Population of this study $(\mathrm{N}=27)$

\begin{tabular}{|c|c|c|}
\hline Groups & Number & Notes \\
\hline (1) Participants from the government & 4 & Government policy-makers \\
\hline (2) University leaders & $\begin{array}{l}S \text { University }=5 \\
Z \text { University }=5\end{array}$ & $\begin{array}{l}\text { Including (vice) president, } \\
\text { directors, and deans (from schools } \\
\text { of engineering and economics). }\end{array}$ \\
\hline (3) Academics & $\begin{array}{l}\mathrm{S} \text { University }=2 \\
\mathrm{Z} \text { University }=2\end{array}$ & $\begin{array}{l}\text { Teachers from schools } \\
\text { of engineering and } \\
\text { economics }\end{array}$ \\
\hline (4) International students & $\begin{array}{l}\mathrm{S} \text { University }=5 \\
\mathrm{Z} \text { University }=4\end{array}$ & $\begin{array}{l}\text { They are in different level of } \\
\text { study (first degree, master, } \\
\text { and doctoral), and come from } \\
\text { different countries including } \\
\text { Russia, Malaysia, the US, Pakistan, etc. }\end{array}$ \\
\hline
\end{tabular}

two different levels in China: a top research university that is also a "Double First-Class"2 university in China, with a higher level of internationalization (S University ${ }^{3}$ ) and a local university with a lower level of internationalization (Z University ${ }^{4}$ ), with participants from different disciplines. Admittedly, these two cases cannot represent the whole of China, but the investigation of perspectives from them can enable us to make a comparison of the policies, strategies, regulations, and relevant practices (e.g., management) about international students between universities at two different levels.

\section{Data collection}

Due to the differences of the participants, there were four sets of interview questions for the above-listed participants in the study. Interview questions for each group were slightly different, but they can be generally divided into the following three broad topics: (1) policies and strategies related to inward international students; (2) management and regulations of international students; and (3) inward student mobility and (global) common goods (see examples of interview questions for university leaders in Appendix 1).

Each interview lasted between 30 and $70 \mathrm{~min}$, depending on the interest of the participants and the natural pace with which the interview moved. Interviews were conducted in both Chinese and English (according to the respondents' requirements) and then transcribed into written form by researchers. Participation in this research was on a voluntary basis, and participants were guaranteed anonymity and confidentiality.

\footnotetext{
2 "Double First-Class" refers to "First-Class University" and "First-Class Discipline" in China.

${ }^{3} \mathrm{~S}$ University is a global research university in China, with a high level of international connectedness and a leading national role, being listed in the top 100 in the Academic Ranking of World Universities (ARWU) and the top 5 in the Best Chinese Universities Ranking. By December 2018, the percentage of international students in S University is about $15 \%$, and one in three undergraduate students of S University has the experience of overseas study. S University has signed various student exchange agreements with more than 100 world leading universities and conducted a wide range of research cooperation with overseas partners (Source: university website).

${ }^{4} \mathrm{Z}$ University is a comprehensive research university with international connectedness and a strong regional mission. It is a provincial university, being listed in the 301-400 in the ARWU and 50-60 in the Best Chinese Universities Ranking. By the end of 2018, the percentage of international students in Z University is about $2.4 \%$. Z University also has exchange programs and research cooperation with overseas universities in certain fields (Source: university website).
} 


\section{Data analysis}

Nvivo12.0 qualitative software and qualitative content analysis (QCA) were used to analyze the interview data. Qualitative content analysis, also called thematic analysis, is one of the most commonly used methods for analyzing qualitative data, with the focus on working with categories (codes) and developing a category system (coding frame) (Mayring 2014). Transcripts were coded according to participants' responses to each question and to the most salient categories (also called themes) emerging across the set of interviews. An initial list of main categories corresponding to the questions asked in the interview was formed deductively; then, as a second step, data were coded with the main categories (e.g., policies and strategies; global common good contributions). Next, compiling text passages of the main categories and forming subcategories inductively on the material; assigning text passages to subcategories (e.g., "scholarship policy" was a subcategory under "policies and strategies"). Last, all categories were refined under more general headings related to the research questions, and a category system was formed.

In the paragraphs that follow, participants in the interviews were referred to by different code names, for the purposes of both ensuring anonymity and facilitating tracing references from the data (see examples of code names for participants in Table 5).

\section{Results and findings}

\section{Inward student mobility and (global) common goods}

Considering the contributions made by inward student mobility to (global) common goods, participants suggested that, academically, it cultivates human resources, retains high-level talents (serving local society), and improves international cooperation; politically, it accelerated international exchanges, which improves mutual understanding and respect; scientifically, it strengthens international scientific research cooperation; and economically, it can be seen as a potential economic growth point (though China has not yet achieved this result) and may expand the influence of destination countries and cities. In general, based on Marginson's (2018) global goods framework, the individualized and common goods at both national and global levels can be summarized in Table 6.

Specifically, for the host country, international students promote cultural exchanges, and they could become cultural ambassadors in the future. For students' home countries, they can bring back advanced knowledge and research outputs, and students studying abroad can also

Table 5 Code names for different participants in interviews

\begin{tabular}{ll}
\hline Code names & Explanation \\
\hline$P G A 1$ & the first participant from the government, who is an official. \\
the second participant in S University, who is a university leader. \\
$P Z A 3$ & the third participant in Z University, who is an academic. \\
PZS5 & the fifth participant in Z University, who is an international student.
\end{tabular}

Notes: $P$, participants; $G A$, participants from the government; $S, S$ University (a top research university with a higher level of internationalization); Z, Z University (a local university with a lower level of internationalization); L, university leaders; A, academics; $S$, international students 
Table 6 Mapping the contributions of inward student mobility in China

\begin{tabular}{|c|c|c|}
\hline & National & Global \\
\hline Individual & - Better employment $(N=6)$ & $\begin{array}{l}\text { - Enriching students' international } \\
\text { experience and vision }(N=8)\end{array}$ \\
\hline Common & $\begin{array}{l}\text { - Increasing host country's soft power }(N=6) \\
\text { - Enhancing the internationalization level of universities and } \\
\text { expanding their international influence }(N=5) \\
\text { - Generating economic growth point }(N=2)\end{array}$ & $\begin{array}{l}\text { - Constructing an international } \\
\text { talents pool }(N=13) \\
\text { - Increasing international exchanges } \\
(N=10) \\
\text { - Increasing international research } \\
\text { cooperation }(N=8) \\
\text { - Improving mutual understanding } \\
\text { and respect }(N=6) \\
\text { - Improving relevant policies and } \\
\text { practices }(N=6) \\
\text { - Diversifying campus culture } \\
(N=4)\end{array}$ \\
\hline
\end{tabular}

be regarded as role models for other students who hoped to study abroad. Eight international students interviewed expressed their willingness to stay for employment or continue further studies in China.

I have a lot of things that I owe China...I probably will stay here, at least for several years, but that depends on whether China will accept me, but of course, I don't take this education for granted, and I hope there is a chance I can make a contribution to China. (PSS3)

Most participants suggested the advantages brought by inward student mobility outweigh the disadvantages. However, university leaders and academics considered the potential disadvantages of inward student mobility include: (1) problem of unfairness $(N=4)$, since international students occupy the opportunities for domestic students, excessively consuming the energy of the administrators as they often pay more attention to international students rather than the domestic students; (2) brain drain of the source countries $(N=1)$. In contrast, two government officials believed that inward student mobility could promote social equity, as it advances the sharing of educational resources, and helps some backward countries' educational development.

I believe inward student mobility in China promotes social equity rather than damages it, because it is good for the sharing of educational resources, and it is also a way to help some countries with less-developed education. (PGA4)

Also, most international students $(N=7)$ did not consider it to be unfair for people like them to access to the experiences and benefits of international education, because the selection of candidates to study in China depends on the ability of the applicants, and the opportunity for international education is on a global basis, and it is beneficial for all.

\section{Policies and strategies related to inward international students}

At the national level, government officials mentioned that China's strategic goal is to host 500,000 international students by 2020 . Meantime, most participants $(N=18)$ mentioned that the funding policy oriented to international students studying in China are very supportive 
(e.g., Chinese government scholarships and provincial funding). In these years, under the framework of "people-to-people exchange", the Belt and Road Initiative as well as other important policies includes international students studying in China as a strategic part $(N=7)$.

Our strategic goal is to recruit 500,000 international students by $2020 \ldots$ this was stated in the Plan of Studying in China... the policies, especially the funding policy, are quite supportive... the Belt and Road Initiative also includes international students studying in China as a strategic part. (PGA1)

Eight participants mentioned the Decree No. 42, i.e., the Administrative Measures for the Enrolment and Cultivation of International Students by Schools issued in 2017, which covers all aspects of international student management. In addition, the assimilative management of international students studying in China becomes a trend, which implies HEIs encourage Chinese and international students to live together thereby increasing mutual respects and understandings $(N=10)$. By doing so, China hopes to have more students who have better knowledge about China, become friends to China, and are on intimate terms with China.

China is now much closer to the centre of the world stage than ever before... we hope more students come to China so as to better understand China, become familiar with China, and finally form friendly relationship with China. (PGA2)

At the university level, policies are more specific, that is, increasing the support for international students; conducting assimilation management to avoid isolation; introducing new types of scholarship; and opening bilingual courses $(N=10)$. $\mathrm{S}$ University's current working guidelines for international students are: expanding size, optimizing structure, improving management, and ensuring quality. As a "Double First-Class" university in China, internationalization is a key component in the development of S University $(N=6)$. Z University focuses on increasing the number of international students and the recruitment of these students from the Belt and Road countries $(N=4)$. In 2015, Z University introduced an internationalization strategy, and highlighted international postgraduate students' recruitment $(N=3)$. Since there is no government scholarship in Z University, it plans to set up its own scholarship for international students.

Our policy and strategy are definitely conforming to the strategy of national development... we pay much attention to Belt and Road countries, so we are now working on attracting students from these countries... we will also establish some additional scholarships. (PZL5)

The majority of government officials and university leaders $(N=10)$ pointed out that the government strategically guides the internationalization of HEIs, and HEIs serve the national goal of attracting international students. All officials and university leaders $(N=14)$ considered relevant policies and strategies to be effective, achieving the expected results. The most frequently mentioned policies and strategies by the interviewees are the Administrative Measures for the Enrolment and Cultivation of International Students by Schools (2017) $(N=6)$; Belt and Road Initiative $(N=5)$; and the Plan of Studying in China $(N=5)$. 


\section{Management and regulations of international students}

At the national level, all four government officials agreed that all international students who are accepted by Chinese HEIs do not have any difficulties in their first entry, and it is necessary for all international students to abide by national laws and regulations. The latest requirement in the Decree No. 42 allows work-study experiences for international students during their study period, and they are encouraged to have internships in China and spend part of their study time to learn more about Chinese society. After graduation, students need to go through certain procedures to obtain a work visa, or they must return home immediately. Participants mentioned that China has relatively tight regulations on foreign nationals' long-term residence, but it welcomes high-level talents to stay $(N=5)$. Undergraduate students cannot stay in China after graduation, and they cannot obtain work permits. The policy for postgraduate students is relatively flexible, and students can obtain an employment visa in free trade zones ${ }^{5}$ in some coastal metropolitan cities $(N=9)$. However, some international students $(N=4)$ are still concerned about the employment issues in China:

We have an information group and the teacher promptly provides relevant employment information... but this is not enough for us, we still face a lot of problems in finding a good job in China. (PSS5)

International students do have some influence on policy-making, for example, the right of residence, entry and exit, and employment, and they play a positive role in promoting policy reforms $(N=6)$. Three interviewees pointed out that when international students are studying and living in China, they are involved in a series of issues related to medical care, social insurance, and other public services; thus, when formulating policies, it is reasonable for the government to consider the needs of international students for their daily life.

International students do have an impact on some policies, for example, the right of residence, entry and exit, and employment issues, and they have played a positive role in promoting these reforms, which is a positive sign. (PGA4)

At the university level, both universities have regulations and requirements on international students based on national policies $(N=12)$. For international students' first entry, they need to have a student visa and go through medical examinations; for in-university supervision, they must obey relevant laws and regulations $(N=14)$. Most international students in our study thought they had favorable experience in Chinese universities which matched their expectations $(N=8)$.

Is this a good place? I must say this place can be described as heaven... I find out that China has already entered the modernized stage... there are so many things we can learn... I guess China goes far beyond my expectations... (PSS1)

Both universities offer specific courses and services for international students. Each international student dormitory has an assistant, and there are also online information groups specifically for international students $(N=9)$. All nine interviewed students received generous

${ }^{5}$ The zone is being used as a testing ground/pilot area for a number of economic and social reforms. 
scholarships from the Chinese government or the universities. They considered both the Chinese government and universities to be very supportive to international students. Basically, international students have few problems on campus, though some of them $(N=3)$ encountered minor problems, for example, they think the administrative procedures are too complicated, and the accommodation is poor in Z University. All nine students put forward that they have never faced issues related to welfare, human rights, personal agency, and dignity, and they feel safer and more comfortable in China than other places.

I don't feel marginalized or disempowered, because I believe "Ru xiang sui su" (Do in Rome as Rome does), and I am obeying the laws of China and trying to see the world through Chinese people' eyes ... in many ways, I am freer, safer and happier here, which I've never felt in my home country... (PSS3)

\section{Discussion}

\section{Discussion framework for inward student mobility from a common goods lens}

The objective of the current research is to identify the (global) common goods produced and augmented by inward student mobility and its relevance to national policies and strategies in China. The findings of this study illustrate that inward student mobility contributes to (global) common goods, and meanwhile policies are compatible to these perceived global common goods to a large extent. Although some problems and tensions among policies, practices, and (global) common goods are observed in this study, measures have been taken by both the Chinese government and HEIs.

As inward student mobility involves different participants (host countries and universities, sending countries, university staff, international students, etc.) simultaneously, and its benefits flow to places at different levels (individual, institutional, local, national, and global); by using the common goods lens, we can interpret inward student mobility within at least the following three sets of relations (see also Table 7): (1) common and individual. This term (common goods) may differentiate the common and individual benefits accruing from inward student mobility; (2) governmental and institutional. This term is useful to explain policies and initiatives in the national context, thus government's influences, support, regulations on HEIs can be reflected; (3) national and global. This concept is multidimensional, and it is helpful to explore the balance, consistency, and tensions between policies and practices concerning inward student mobility at different levels (Deneulin and Townsend 2007; UNESCO 2015; Marginson 2018; Tian and Liu 2019).

Table 7 A framework for inward student mobility from a common goods view

\begin{tabular}{llll}
\hline Sets & & Dimensions & Keywords \\
\hline Set 1 & Common & Individual & Benefit \\
Set 2 & Governmental & Institutional & Influence \\
Set 3 & National & Global & Balance \\
\hline
\end{tabular}

Source: Summarized by the authors 


\section{Benefit and balance (Set 1 and 3): contributions of inward student mobility in China to (global) common goods}

As we have defined in this paper, common goods are multilevel, including local, national, and global common goods. Based on the research findings, inward student mobility in China contributes to (global) common goods in the following five aspects, which are highly valued by interviewees from both the government and HEIs:

(1) Talents with global perspectives and respect to other cultures. Through international education, international students will become global citizens who care for the whole world and make contributions to form a more inclusive, tolerable, and equal world.

(2) The wider sharing of educational resources. Inward student mobility intensifies educational cooperation between different countries and accelerates the process of mutual recognition of credit and certificate, which boosts the sharing of educational resources.

(3) Increased cultural exchanges, deeper mutual understandings, and diverse campus culture. International students help to form a more diverse and inclusive campus culture, and they can also be portrayed as cultural ambassadors to press ahead cooperation and exchanges between the host country and their home countries.

(4) The improvement of policies and practices. The presence of international students may shape higher education policies and practices to be more efficiency-, service-, and reputation-driven.

(5) The potential economic growth point. Inward student mobility can be regarded as economic agent or driver of knowledge and eventually of economic growth. For some universities, recruiting international students is an alternative source of revenue to ensure their financial sustainability.

In fact, the economic aspect of inward student mobility is particularly strong among AngloSaxon countries (Geddie 2015) and extensively studied as the "marketization approach" to international education (Findlay et al. 2017). However, our results suggest that China gives less weight to the economic aspect of inward student mobility at this moment, agreeing with Jiang (2010b) that the economic benefits of international students are not a focus of higher education in China.

Nevertheless, Chinese interviewees highlight the increased soft power brought by inward student mobility, which can be regarded as a national common good within a national boundary. Inward student mobility intensifies academic and scientific exchanges which are central to soft power theory, and this can also be inspired by observations of how the US has gained friends among political elites of hostile countries by means of student exchanges (Nye 2004; Ma and Zhou 2018). This theory suggests that international students with pleasant firsthand experiences of studying abroad will admire the host country's academic, social, and political system and, in turn, nudge or steer cooperation between their home countries and the host country, push education, society, and politics at home in the direction desired by the country they studied and lived in (Haugen 2013). This is not only an opportunity for Chinese language and culture to enter the global platform but also for soft power expansion.

In general, these are the perceived potential national and global common goods created by inward student mobility in China, which undoubtedly reveal the unique value of inward international students. Despite that, the research findings suggest that attracting and educating international students in China is never a pure business transaction with only market and 
economic orientations, as both the Chinese government and HEIs attach great importance to the development and welfare of international students who desire educational, social, personal, and professional development that underpins the process of "becoming" and "self-formation" (Marginson 2014; Tran 2016). Therefore, international education in China tends to be a practice of reciprocity, within the concept of the "ethics of care" (Blackburn 1997; Abdullah et al. 2017), which suggests both parties (international students and HEIs) should ensure each party is involved in the benefits of internationalization from their interaction and have genuine concern over the well-being of each other in the provision of international education. In this sense, international education in China could be viewed as a global common good itself, since both parties need each other to achieve their intended goals, which thinks highly of collective endeavor, shared participation/engagement, inclusion, and responsibility, meshing with UNESCO's (2015) definition of global common goods.

Hence, international students should never be simply treated as "cash cows" and their desire to have a life-changing experience (through international education) should be valued. In turn, the cared for (international students) should acknowledge the energy and efforts invested by the carer (HEIs) to enhance the value of the relationship between both parties. In light of this, the narrative of ethical caring could build a conducive intercultural ecosystem to support the internationalization activities, boosting greater learning between students and university staff, and ensuring mutuality in strategies developed for cooperation and collaboration with foreign partners, which is a key virtue in internationalization from the outset (Blackburn 1997; Abdullah et al. 2017).

\section{Influence and balance (Set 2 and 3): sound development of policies and practices for international students studying in China}

The results of this study show that in the Chinese context, inward student mobility has not only emerged as a significant favorable pull factor for the internationalization of higher education but also contributes significantly to both national and global common goods. By examining various recent national policies and university strategies, it is easy to conclude that the inward student mobility has been given a special priority in the Chinese context. This reflects the positive attitude of both the Chinese government and HEIs, and contradicts the idea that the emphasis laid on international students is less in China, and the view that international students are less important to Chinese universities, because they are not seen as human resources due to their generally low academic performance (Jokila 2015).

However, some researchers believe that the Chinese government's efforts to promote inward student mobility are only to achieve the policy objectives of diplomacy and education, while ignoring the contributions of international students in culture, politics, and economy (Cheng et al. 2013). Obviously, this comment is not objective, because the findings of this study provide evidence that promoting mutual understandings and improving the quality of higher education through international education is an established strategy for the development of higher education in China, and this strategy does not exist in isolation. It falls in line with China's development goals of improving national soft power and cultural influence (Wang et al. 2014). Also, the neoliberals believe that China's efforts for educational improvement are characterized by export (Zheng 2010). This comment seems to simply equate the internationalization of higher education with a commercial trade activity, overlooking the internationalization of Chinese higher education contains unique cultural appeal. Chinese culture advocates "harmony in diversity" and believes that different value systems should coexist harmoniously. 
According to our research findings, the dissemination of Chinese culture through international education is currently an important tool for China to build better political and economic relations with other countries, and the "bridge" is the international students who understand and respect Chinese culture, show kindness to China, and are on intimate terms with China. This is aligned with Schulte's (2012) idea that Chinese education actually takes place at the interface of global ideas and national strategies. Internationalization and nationalism are not necessarily in conflict with each other in China; instead, special cultural aspects could benefit from international relations ( $\mathrm{Gu} 2001)$.

Specifically, this study uncovers the different policies and strategies of internationalization between the two case universities. Due to the different institutional needs and developmental goals in the process of internationalization, the university with lower degree of internationalization lays more emphasis on the quantity of international students, while the university with higher level of internationalization has shifted its focus from merely increasing the number of international students to improving the quality of international students as well as diversifying students' source countries. This strategy is supported by Wang et al.'s (2014) study, which propose that the effectiveness international education strategy mainly hinges on the quality, not the number, of international students. Tellingly perhaps, the research results also illustrate that $\mathrm{Z}$ university gives close attention to attracting students from the Belt and Road countries. On the one hand, this is due to Z University's geographic location (it is located near the southern Chinese border) which makes it have a unique advantage to attract international students from neighboring NSR countries; on the other hand, this reflects that countries working with China on the Belt and Road initiative are likely to see more opportunities in educational cooperation and involvement (Chen and Wen 2018).

However, there are some problems and tensions among the policies, practices, and (global) common goods that can be observed in the results and findings, for example, the employment issue. Though both the Chinese government and HEIs endeavor to attract more international students studying in China and build a global talent pool, the employment mechanism is not in place, failing to retain talents who hope to work and stay in China. But very recently, a few coastal metropolitan cities in China have re-tailored their policies on international student employment (but only for postgraduate students) to secure highly skilled international graduates, and potentially, these policies may be expanded to the whole country within the coming years.

\section{Conclusion}

The present research is both people concerned and policy focused, addressing issues by investigating perspectives from people directly involved in the process and examining some key policy documents related to inward international students in China. The findings of this study reveal that inward student mobility brings benefits to China and contributes to global common goods flowing worldwide, which can also be regarded as a reason for the supporting of national and institutional policies and strategies on international students. Though there are also some tensions in the policies and practices for international students (e.g., employment and management issues), relevant efforts have been exerted to address them. Most importantly, this study suggests that international education in China, as an essential part of higher education internationalization, can be seen as a global common good, which emphasizes collective endeavor, shared participation, inclusion, and responsibility. Nevertheless, the current coronavirus (COVID-19) threat may cast a shadow over booming international education in China and affect China's ability to attract more 
international students in a certain period. This puts forward new requirements for both countries and universities (not only China and Chinese universities) to raise awareness of the need for risk management and crisis response strategies to ensure sustainability that highlighted by UNESCO (2015) as an indispensable role and responsibility of diverse stakeholders in the collective quest for the common good.

Acknowledgments This study was partly funded by the ESRC (Economic and Social Research Council) and HEFCE (Higher Education Funding Council for England) (grant number: ES/M010082/1).

\section{Appendix 1}

Interview questions for university leaders

1. What are the policies and strategies of your institution in relation to inward student mobility?

2. In your HEI's internationalization strategy, what priority do you place on inward student mobility? How internationalized is your HEI?

3. What is the profile of international students in your institution at present? How does this compare to other institutions? Has it changed over time?

4. [only for those leaders responsible for detailed administration of international students] What are the requirements of migration policy and national security as they directly affect inwardly mobile cross border students, including (1) initial entry, (2) regulation during the student sojourn, (3) the transitions from student status to graduate work and/or residency?

5. Are there other areas of government policy, apart from policies on education, migration, and national security, which, in your opinion, affect inwardly mobile cross border students?

6. How have policy changes in recent years impacted the student profile, and the student experience? Looking at inward student mobility as a whole, not just your HEI, to what extent are inward student mobility policies and strategies implemented successfully, given the policy objectives, and also other policies? Are there unintended outcomes?

7. What are the benefits of student mobility and risks/disadvantages for the HEI?

8. What are the main global common goods, benefits flowing not just to your country but to other countries, including the countries of student origin, that are created or augmented by inward student mobility in your nation?

9. What student fees are charged to international students, if any? What scholarships are offered? On what basis? What services in your institution are available to inwardly mobile international students, and targeted to those international students?

10. What are the experiences of inwardly mobile international students in the country of education, in relation to issues of welfare, human rights, personal agency and dignity? What problems and limitations face these students?

11. [Only for selected leaders likely to tackle the question effectively] What are the benefits of a degree from your institution, when students return to their home countries? What do they learn at your institution, or gain in other ways, that is not available in their home country? Do graduate cross-border students keep in touch with your institution after they leave?

12. [Only for selected leaders likely to tackle the question effectively] In your opinion, what are the effects of inward student mobility in your country - positive and negative - in the countries from which the students come? 


\section{References}

Abdullah, D., Abd Aziz, M. I., \& Mohd Ibrahim, A. L. (2017). The stories they tell: understanding international student mobility through higher education policy. Journal of Studies in International Education, 21(5), 450-466.

Benson, D., \& Jordan, A. (2011). What have we learned from policy transfer research? Dolowitz and Marsh revisited. Political Science Review, 9(3), 366-378.

Blackburn, M. (1997). Internationalization: some ethical challenges. In Proceedings of the 1997 annual conference of the Higher Education Research and Development Society of Australasia (pp. 95-103). Adelaide, SA: Flinders University Press.

Boyadjieva, P., \& Ilieva-Trichkova, P. (2019). From conceptualization to measurement of higher education as a common good: challenges and possibilities. Higher Education, 77(1-2), 1047-1063.

Cao, C., Zhu, C., \& Meng, Q. (2016). A survey of the influencing factors for International Academic Mobility of Chinese University students. Higher Education Quarterly, 70(2), 200-220.

Choudaha, R. (2017). Three waves of international student mobility (1999-2020). Studies in Higher Education, 42(5), 825-832.

Chen, Q., \& Wen, W. (2018). "Yi dai yi lu" chang yi xia lai hua liu xue sheng jiao yu: Shi ming, tiao zhan he dui ce [international education under the Belt and Road Initiative: missions, challenges and solutions]. Gao xiao jiao yu guan li, 12(3), 28-33.

Cheng, J. F., \& Huang, M. X. (2008). Lun lai hua liu xue sheng jiao yu li shi fen qi wen ti [the historic stages of international education in China]. Zhong guo gao jiao yan jiu, 12, 19-22.

Cheng, J. F., Hou, S. F., \& Chen, S. L. (2013). Strategic choices of development of China international education in the early twenty-first century, In Proceedings of 19th International Conference on Industrial Engineering and Engineering Management (pp. 259-269). Berlin, Heidelberg: Springer.

Deneulin, S., \& Townsend, N. (2007). Public goods, global public goods and the common good. International Journal of Social Economics, 34(1/2), 19-36.

de Wit, H., Ferencz, I., \& Rumbley, L. E. (2013). International student mobility: European and US perspectives. Perspectives: Policy and Practice in Higher Education, 17(1), 17-23.

Fang, B., \& Wu, Y. Y. (2016). Gao deng jiao yu lai hua liu xue sheng de bian hua qu shi yan jiu—Ji yu jin shi wu nian tong ji shu ju de fen xi [a study on the changing trend of international students studying in Chinabased on the recent 15-year statistics]. Gao deng jiao yu yan jiu, 37(2), 19-30.

Findlay, A., McCollum, D., \& Packwood, H. (2017). Marketization, marketing and the production of international student migration. International Migration, 55(3), 139-155.

Geddie, K. (2015). Policy mobilities in the race for talent: competitive state strategies in international student mobility. Transactions of the Institute of British Geographers., 40(2), 235-248.

Gu, M. (2001). Modernization and education in China's cultural traditions. In M. Gu (Ed.), Education in China and abroad: Perspectives from a lifetime in comparative education (A. L.J. Chan, trans.) (pp. 101-110). Honk Kong: Comparative education research Centre, Hong Kong University.

Han, W. C. (2014). Jing ji quan qiu hua shi jiao xia de guo ji ren li zi yuan guan li wen ti yan jiu—Ji yu lai hua liu xue sheng jiao yu guan li de si kao [a study on international human resource management from the perspective of economic globalization - based on the education management of international students in China]. Guan li shi jie, 8, 182-183.

Haugen, H. Ø. (2013). China's recruitment of African university students: policy efficacy and unintended outcomes. Globalization, Societies and Education, 11(3), 315-334.

Hollenbach, D. (2002). The common good and Christian ethics. Cambridge: Cambridge University Press.

Jiang, K. (2010a). Lai hua liu xue sheng jiao yu de ping jing wen ti ji jie jue cuo shi [the bottleneck problems and solutions of international education in China]. Da xuе jiao yu ke xue, 2, 21-25.

Jiang, K. (2010b). Lai hua liu xue sheng jiao yu de zhan lue ding wei: Ji yu duo yin su de fen xi [strategic positing of international education in China: an analysis based on multi-factors]. Zhong guo gao jiao yan jiu, 5, 17-20.

Jin, W. (2012). Gai ge Kai fang yi lai zhong guo Gao deng jiao yu guo ji hua zheng ce de Shan bian: Ji yu shu ju yu zheng ce de lian jie [the evolution of China's higher education internationalization policies since reform and opening up: based on the connection of data and policies]. Zhong guo ren min da xue jiao yи xue kan, 4, $29-48$.

Jokila, S. (2015). The internationalization of higher education with Chinese characteristics: Appadurai's ideas explored. Asia Pacific Journal of Education, 35(1), 125-139.

Kehm, B. M., \& Teichler, U. (2007). Research on internationalization in higher education. Journal of Studies in International Education, 11(3/4), 260-273.

Knight, J. (2012). Student mobility and internationalization: trends and tribulations. Research in Comparative and International Education, 7(1), 20-33.

Locatelli, R. (2018a). Education as a public and common good: reframing the governance of education in a changing context. UNESCO education research and foresight working papers. No 22. Retrieved January 1 , 2020 from http://unesdoc.unesco.org/images/0026/002616/261614E.pdf. 
Locatelli, R. (2018b). Higher education as a public and common good. Lecture delivered at the CGHE, UCL, London, 8th February. Retrieved January 1, 2020 from http://www.researchcghe.org/perch/resources/highereducation-as-a-public-and-common-good-rl-08-feb.-seminar.pdf.

Ma, J. L., \& Zhou, Z. Y. (2018) "Yi dai yi lu" yan xian Gao duan liu xue sheng mian lin de tiao zhan ji qi dui ce [the challenges and solutions for high-level international education in countries within the belt and road initiative]. Gao deng jiao yu yan jiu, (1), 100-106.

Marginson, S. (2014). Student self-formation in international education. Journal of Studies in International Education., 18(1), 6-22.

Marginson, S. (2016a). The outline of project 1.2: Internationalization of HE as a public good. London: Centre for Global Higher Education.

Marginson, S. (2016b). Higher education and the common good. Melbourne: Melbourne University Publishing. Marginson, S. (2018). World higher education under conditions of national/global disequilibria, CGHE Working paper 42. Retrieved January 1, 2020 from https:/www.researchcghe.org/perch/resources/publications/wp422.pdf.

Mayring, P. (2014). Qualitative content analysis: Theoretical foundation, basic procedures and software solution. Austria: Klagenfurt.

Ministry of Education of China. (2000-2019). Concise statistics for international students in China. Beijing: Department of International Cooperation and Exchange in the Ministry of Education.

Murphy-Lejeune, E. (2008). The student experience of mobility, a contrasting score in M. Byram \& F. Dervin (Ed.), Students, Staff and Academic Mobility in Higher Education (pp. 12-30). Newcastle, UK: Cambridge scholars Publisher.

Nye, J. S. (2004). Soft power: The means to success in world politics. New York: Public Affairs.

OECD. (2019). Education at a glance 2019: OECD indicators. Paris: OECD Publishing.

Riaño, Y., Van Mol, C., \& Raghuram, P. (2018). New directions in studying policies of international student mobility and migration. Globalization, Societies and Education, 16(3), 283-294.

Schulte, B. (2012). World culture with Chinese characteristics: when global models go native. Comparative Education, 48(4), 473-486.

Tian, L. (2019). World-class universities: A dual identity related to global common good(s). In Y. Wu, Q. Wang, \& N. C. Liu (Eds.), World-class universities: Towards a global common good and seeking national and institutional contributions (pp. 93-113). Rotterdam: Brill Sense Publishers.

Tian, L., \& Liu, N. C. (2019). Rethinking higher education in China as a common good. Higher Education, 77(4), 623-640.

Tran, L. T. (2016). Mobility as 'becoming': a Bourdieuian analysis of the factors shaping international student mobility. British Journal of Sociology of Education, 37(8), 1268-1289.

UNESCO. (2015). Rethinking education: Towards a global common good? Paris: UNESCO Retrieved January 28, 2017 from http://unesdoc.unesco.org/images/0023/002325/232555e.pdf.

Walker, M., \& McLean, M. (2013). Professional education, capabilities and the public good: The role of universities in promoting human development. London: Routledge.

Wang, H. C., Dai, N., \& Liu, H. G. (2014). Quan qiu hua bei jing xia de guo ji xue sheng liu dong yu zhong guo zheng ce xuan ze [international student mobility and China's policy choice under the background of globalization]. Xia men da xие хие bao (zhe xue she hui ke xue ban), 2, 149-156.

Yu, Z. F. (2009). Gai ge Kai fang 30 nian de lai hua liu xue sheng jiao yu [international education in China in the past 30 years since the reform and opening-up]. Beijing: Beijing Language and Culture University Press.

Yang, Q. G. (2018). Tui dong Gao deng jiao yu quan qiu liu dong jian she ren lei ming yun gong tong ti [promoting the global mobility in higher education and building a community of shared future for mankind]. China: Chinese Social Science Net, Retrieved December 28, 2018 from http://www.cssn. cn/zx/bwyc/201809/t20180906_4555415_1.shtml

Zheng, J. (2010). Neoliberal globalization, higher education policies and international student flows: an exploratory case study of Chinese graduate student flows to Canada. Journal of Alternative Perspectives in the Social Sciences, 2(S1), 216-244.

Publisher's note Springer Nature remains neutral with regard to jurisdictional claims in published maps and institutional affiliations. 